\title{
Visually evoked cortical potentials in the evaluation of homonymous and bitemporal visual field defects
}

\author{
H. G. H. WILDBERGER,* G. H. M. VAN LITH, R. WIJNGAARDE, \\ AND G. T. M. MAK \\ From the Eye Hospital, Erasmus University, Rotterdam, The Netherlands
}

Ever since visually evoked cortical potentials (VECPs) were first used as a diagnostic aid the important question has been whether they could detect visual field defects. In earlier investigations (Vaughan, Katzman, and Taylor, 1963; Vaughan and Katzman, 1964; Kooi, Güvener, and Bagchi, 1965) light-flash stimulators illuminating the entire retina were used and the bioelectrical responses from both hemispheres were compared. Because asymmetries between the hemispheres were also found in normal people only differences of 50 per cent or more between the responses of the right and left hemisphere were considered significant. Later, methods of stimulating the temporal and nasal parts of the retina separately with flash and checkerboard stimulation were introduced (Cobb and Morton, 1970; Biersdorf, 1974). Finally, Regan and Heron (1969) devised a sophisticated method of separating the signals from retinal areas stimulated simultaneously. There are few reports of the clinical application of these techniques. This paper reports our experience in this field.

\section{Patients and methods}

Six patients with homonymous hemianopia (due in five cases to a vascular insult and in one case to a tumour in the parieto-occipital region) and six patients with a bitemporal hemianopia (all with a tumour in the region of the chiasm) were examined, the latter group both pre- and postoperatively. A projection system was used for the checkerboard-reversal stimulation. The screen subtended a $24^{\circ}$ visual angle while the individual checksize was $\frac{1}{2}^{\circ}$. The modulation depth of the black and white squares was 90 per cent. The reversal frequency amounted to $8 \mathrm{~Hz}$. During full-field checkerboard stimulation the patient had to fix a small spot in the centre of the illuminated screen. After that a halffield stimulation was applied by presenting only the vertical half of the original screen. In the latter the

*Supported by the Swiss National Science Foundation as a visiting scientist

Address for reprints: Dr G. H. M. van Lith, Eye Hospital, Erasmus University, Rotterdam, Holland patient had to fix a small light attached to the right or left border just outside the stimulating field. A vertical strip to avoid possible interhemispherical callosal projections (Regan and Cartwright, 1970) was not used.

The electrodes were placed according to the EEG Io to 20 per cent system. For our purpose we used a smaller distance for the electrode position in the midline -namely, 5, 15, and 25 per cent above the inion. From these both a bipolar and a referential lead were used. The bipolar registration was made from the 5 to the 25 per cent position and the referential registration from the 15 per cent position to the right earlobe, the left earlobe being earthed. Furthermore, two bipolar registrations were made from the right and left hemisphere- that is, from $\mathrm{O}_{2}$ to $\mathrm{C}_{4}$ and from $\mathrm{O}_{1}$ to $\mathrm{C}_{3}$.

In full-field stimulation the amplitude measured from the referential lead appeared to be normal in our set-up (above $7.5 \mu \mathrm{V}$ ), whereas in half-field stimulation only a difference in amplitude of more than 50 per cent between the hemispheres was considered significant. With a reversal frequency of $8 \mathrm{~Hz}$ we obtained steady-state VECPs, so we measured the phase instead of peak latencies. The latter can be measured only with transient VECPs obtained by low frequency stimulation (Halliday, McDonald, and Mushin, 1972). For the phase we measured the time between the trigger of the averager and the first positive peak of the sinusoidal response (marked by horizontal line in Figs $I$ and 3 ). The normal values are within I $8 \mathrm{~ms} \pm 9 \mathrm{~ms}$.

In half-field stimulation the amplitudes and phases from the stimulated hemispheres were compared. On stimulating the right eye, for example, the response from the left hemisphere, arising from temporal halffield stimulation, was compared with the response from the right hemisphere, arising from nasal half-field stimulation (Fig. 2). These differences were more pronounced than those in the responses from the midline electrodes. Nevertheless, examination of normal individuals showed that a 50 per cent criterion had to be applied to them also. A difference of more than Io $\mathrm{ms}$ in the phase was considered to be pathological.

\section{Results}

HOMONYMOUS HEMIANOPIA

Figs $I$ and 2 show the VECPs in a 52-year-old patient after a cerebral vascular accident resulting 


\section{$1 / 2^{\circ}$}

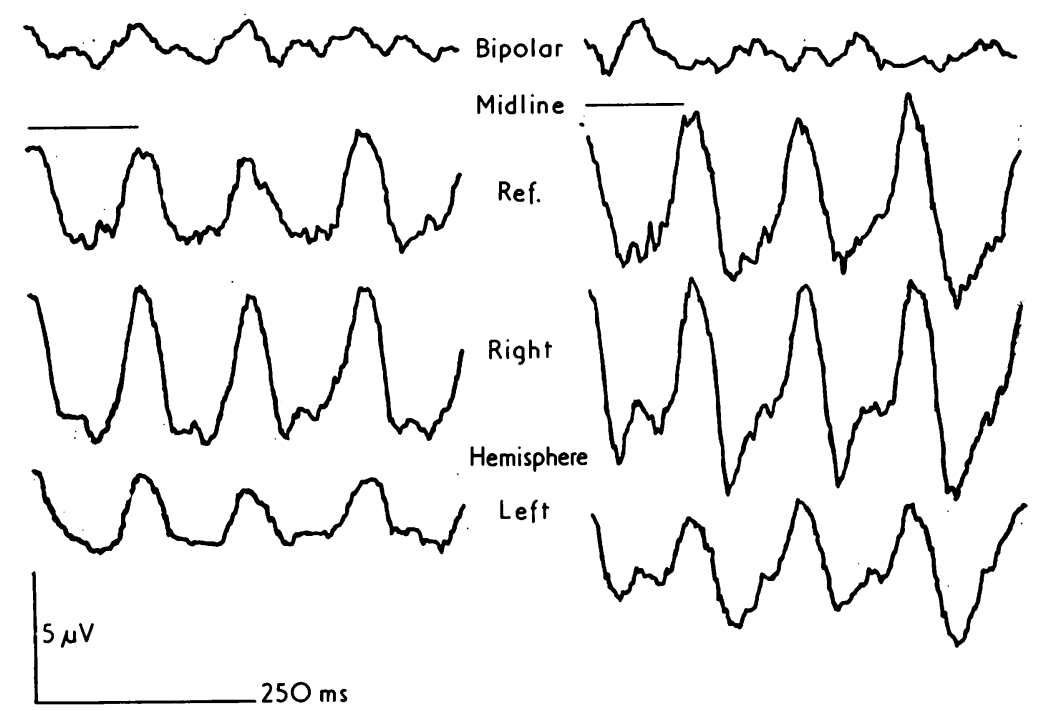

FIG. I VECPs from right and left eye of patient with incomplete homonymous hemianopia to right. Full-field stimulation. Upper recordings are bipolar registrations in midline; second recordings are referential registrations from midline to right earlobe; third and lower recordings are bipolar registrations from right $(R)$ and left (L) hemisphere. Phase marked by horizontal line above recording. In all figures upward deflexions indicate positive polarity

in an incomplete homonymous hemianopia to the right without sparing of the macula. Full-field stimulation (Fig. I) showed slightly reduced amplitudes, while the phase (horizontal line to the first peak of the referential response) was normal for both eyes. There was a marked difference in amplitude, however, between the hemisphere responses, indicating a left-sided cerebral disturbance. Temporal half-field stimulation (Fig. 2) gave from the right eye, in accordance with the visual field defect, much lower responses than nasal half-field stimulation. There was also a phase difference.

Differences in amplitude and phase were greatest between the responses of the directly stimulated hemispheres. A small response was obtained from the non-stimulated left hemisphere after nasal half-field stimulation. This response may have been transmitted by intercallosal connexions and may indicate that the seat of the lesion was not on a cortical level (Mitchell and Blakemore, 1970). The findings in visual field and VECPs in the left eye were of the same kind as those in the right eye.

Of the six patients examined only two showed slightly reduced amplitudes in the midline leads after full-field stimulation, while the phase was always normal. A 50 per cent difference in amplitudes between the hemispheres after full-field stimulation was present in three cases. With halffield stimulation a difference of more than 50 per cent was seen in four patients and of less than 50 per cent in one. One patient showed no difference; his visual field defects were peripheral.

\section{BITEMPORAL HEMIANOPIA}

Figs 3, 4, and 5 show the VECPs in a 63-year-old patient with a chromophobe adenoma. After fullfield stimulation (Fig. 3) the amplitudes were obviously reduced on the left eye. A pathological phase shift (horizontal lines) was seen from both eyes. After full-field stimulation of the right eye the responses from the left hemisphere were smaller than those from the right; after full-field stimulation of the left eye the responses from the right hemisphere seemed to be somewhat more impaired. Half-field stimulation of the right eye (Fig. 4) again gave the greatest difference in amplitude and phase when the curves from the directly stimulated hemispheres were compared.

The result was clear although the visual field defect was limited only to the temporal superior quadrant of the two most inner isopters. After the operation the visual field defect became much smaller (Fig. 5). The difference in amplitude after half-field stimulation was about 30 per cent 

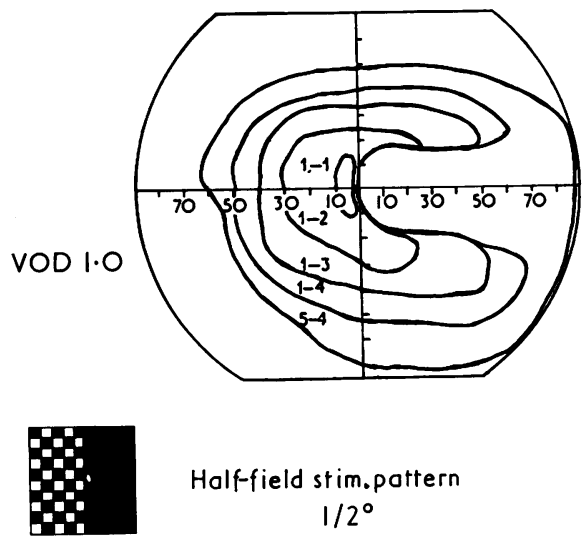

Half-field stim.pottern

$1 / 2^{\circ}$

FIG. 2 Homonymous hemianopia to right, same patient as in Fig. I.

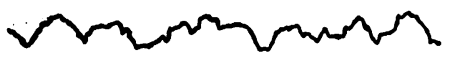

Bipolar

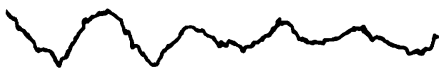

$\int^{n}$

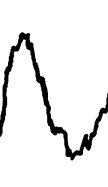

Midline
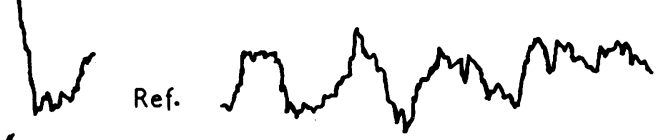

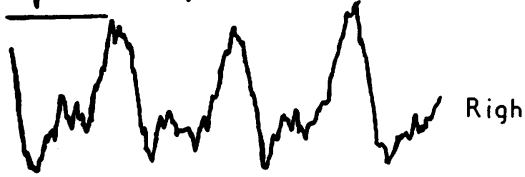

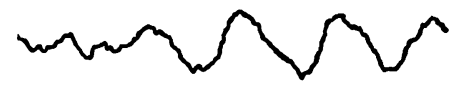

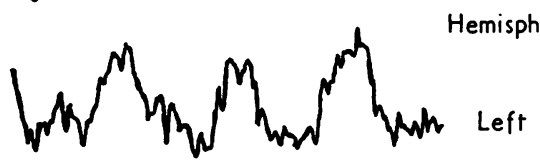

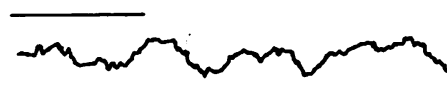

Half-field stimulation of right eye. Responses from nasal half field on left, from temporal half field on right whereas the phase difference was still significant.

Even on the side where the visual acuity was not yet limpaired reduction of amplitude and phase shift were the most important findings in our six patients when examined before the operation with full-field stimulation. The decrease in amplitudes were not so great when only quadrant field anopias were present. Even then significant differences could be found by half-field stimulation.

After operation the amplitudes remained reduced in half of the cases and in two patients showed a doubling of the peaks (Fig. 5, nasal stimulation), a phenomenon which is often seen in the recovery period of optic neuritis. The phase tended to return to normal from the less affected eye. The difference between the hemispheres after full-field stimulation or half-field stimulation remained when there was a large, persisting visual field defect.

\section{Discussion}

Earlier studies (Vaughan and others, 1963; Kooi and others, 1965; Oosterhuis, Ponsen, Jonkman, and Magnus, I969) pointed out the difficulties in differentiating between normal variations in the flash VECPs and the abnormal, the latter appearing as a reduction of the early components (waves $I$, 

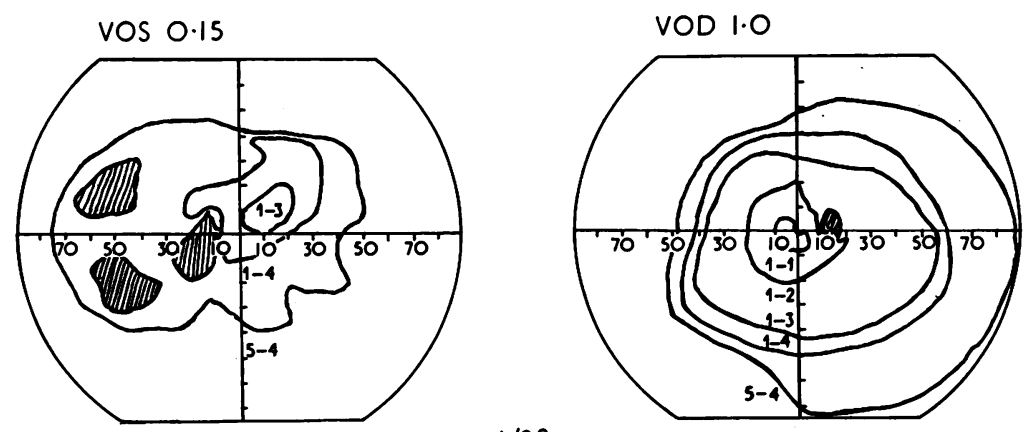

\section{$1 / 2^{\circ}$}

FIG. 3 Preoperative VECPs from right and left eyes of patient with bitemporal hemianopia after full-field stimulation

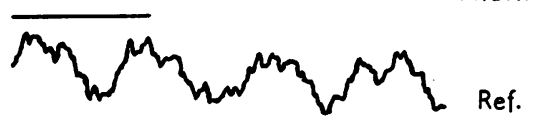
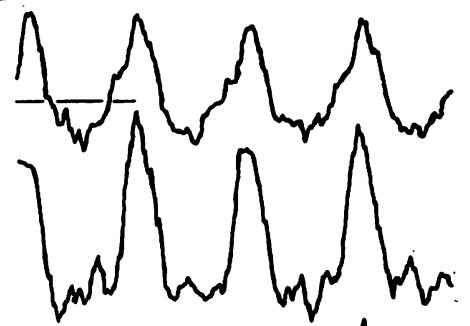

II, and III according to Cigánek's nomenclature). Although VECPs evoked by flash stimulation of low frequency cannot directly be compared with VECPs from pattern-reversal stimulation of a higher frequency ('steady-state' responses) as used in this investigation, our results are comparable with those in the studies referred to.

The difference between homonymous and bitemporal hemianopia is that in the latter the visual input is disturbed more at the periphery, whereas in homonymous hemianopia the site of generation of the VECP itself may be impaired. Oosterhuis and others (1969) concluded that the VECPs are not determined only by the visual pathways and the visual projection areas, since other regions may also be affected and abnormal EEGs may also influence the VECPs. Our investigations in homony- N mous hemianopia, however, did not support this view. The VECPs were probably not interfered with by influences from outside the visual $\mathbb{\omega}$ system any more than in the case of bitemporalo hemianopia.

The difference between cases of homonymous $\overparen{\mathscr{D}}$ hemianopia, with and without macular sparing, was ${ }^{+}$ inapparent. Our mode of stimulation with rather ${ }^{T}$ large checksizes, producing a luminance component, $\frac{P}{\oplus}$ stimulates the paramacular areas more, where the $\stackrel{9}{\square}$ influence of pericallosal connexions is small. This $\varrho$ means that the effects of our stimulus were similar to those of the sinusoidally modulated flicker used 0 by Regan and Heron (1969), which is unable to응 detect macular sparing. 


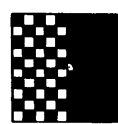

Holf-field stim.pottern $1 / 2^{\circ}$
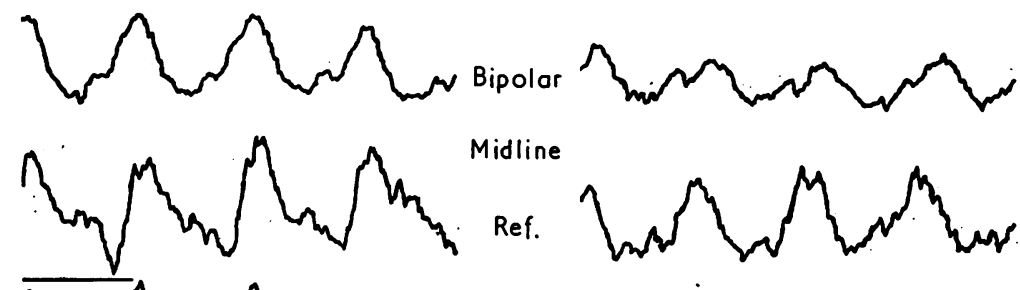

FIG. 4 Same patient as in Fig. 3 . Preoperative VECPs from right eye : nasal stimulation on left, temporal stimulation on right

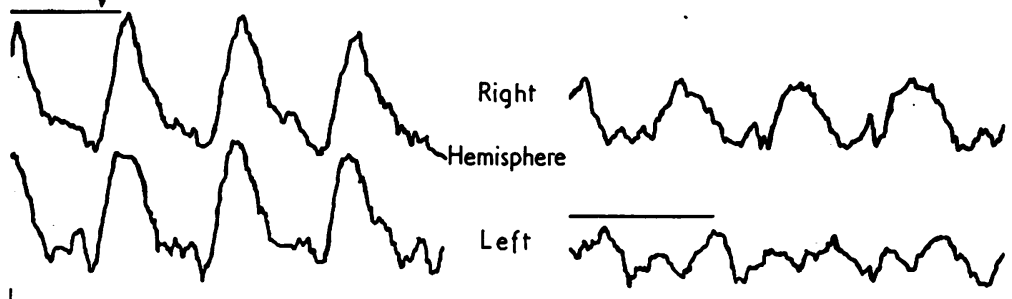

$5 \mu \mathrm{V}$

$250 \mathrm{~ms}$

In bitemporal hemianopia, optic nerves and chiasm are often compressed to a thin cord. Obviously not only are the crossing fibres from the nasal retinae then impaired but also those from the temporal halves. This may occur with rather good nasal visual fields, whereas the VECPs are much reduced and delayed. Pressure of a tumour on the optic nerves may give various clinical pictures. When there is unilateral neuritis the VECPs are not of much help in differentiation. A clear-cut situation, as in the case of a split chiasm (Fisher, Jampolsky, and Scott, I968; Lehmann, Kavanagh, and Fender, 1969) where the fibres from the temporal halves are intact, is seldom seen. In the acute stage of neuritis or pressure on the optic nerves the responses are often very low, near to the noise level (van Lith and Mak, I974). In these cases differences in amplitudes or phases cannot reliably be measured.

\section{Summary}

Visually evoked cortical potentials were studied in six patients with a homonymous and six with a bitemporal hemianopia by presenting a pattern-reversal stimulus separately to a temporal or nasal retinal area and by recording the responses from leads over the hemispheres. Homonymous visual field defects are characterized by a reduction of VECPs from the affected hemisphere. The disturbance of VECPs in bitemporal hemianopia is more serious, since the fibres from both retinal halves may be damaged by a chiasm tumour.

\section{References}

BIERSDORF, W. R. (I974) Docum. ophthal. (Den Haag), 4, 249

COBb, w. A., and MOrTon, H. B. (1970) F. Physiol. (Lond.), 208, 39

FISHER, N. F., JAMPOLSKY, A., and scotT, A. B. (1968) Amer. F. Ophthal., 65, 237

HALLIDAY, A. M., MCDONALD, W. I., and MUSHIN, J. (I972) Lancet, I, 982

KOOI, K. A., GÜVENER, A. M., and BAGCHI, B. K. (1965) Neurology (Minneap.), 15, 84I

LEHMANN, D., KAVANAGH, R. N., and FENDER, D. H. (1969) Electroenceph. clin. Neurophysiol., 26, 193

MitChELl, D. E., and BLAKEMORE, C. (1970) Vision Res., 10, 49

OOSTERHUis, H. J. G. H., PONSEN, L., JONkMAN, E. J., and MAGNUS, o. (1969) Electroenceph. clin. Neurophysiol.,

27,23 

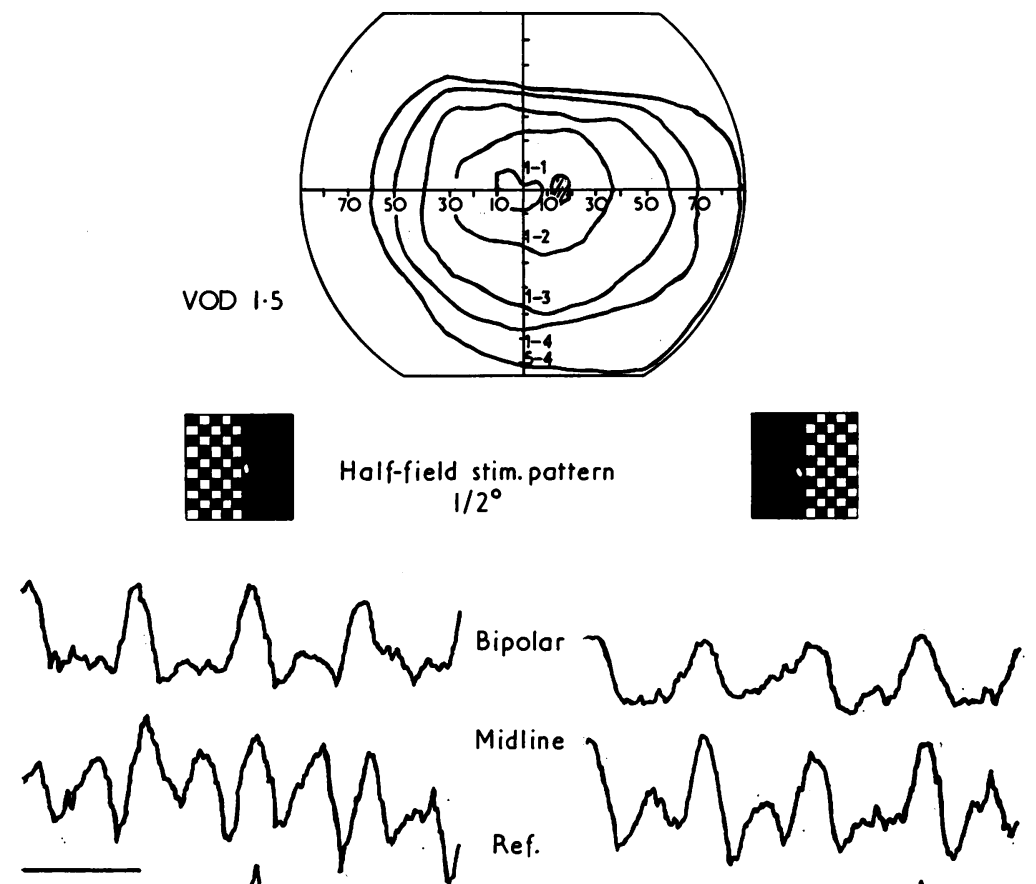

FIG. 5 Half-field stimulation of same eye as in Fig. 4 after operation
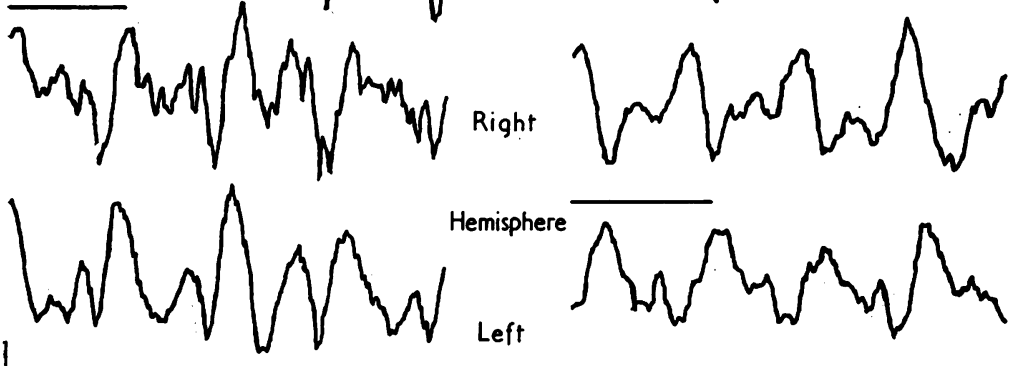

$5 \mu \mathrm{V}$

$250 \mathrm{~ms}$

REGAN, D., and CARTWRIGHT, R. F. (1970) Ibid., 28, 314

, and Heron, J. R. (1969) $\mathcal{F}$. Neurol. Neurosurg. Psychiat., 32, 479

VAN LITH, G. H. M., and MAK, G. T. M. (1974) Docum. ophthal. (Den Haag), 4, 375

vaughan, H. G., and katzman, R. (1964) Ann. N.Y. Acad. Sci., Ir2, 305

,-- , and TAYLOR, J. (1963) Electroenceph. clin. Neurophysiol., 15, 737 